\title{
Emotional Intelligence and Managerial Communication
}

\author{
Tiffany Nguyen \\ Prairie View A\&M University \\ Shayla White \\ Prairie View A\&M University \\ Kenneth Hall \\ Prairie View A\&M University \\ Reginald L. Bell \\ Prairie View A\&M University \\ Wayne Ballentine \\ Prairie View A\&M University
}

Educational credentials and work experience are not enough to become an effective manager. In this article, we explore emotional intelligence (EI) and its effects on managerial communication. Our findings show continuous effort to improve your EI leads to enhanced communication skills, better team environments and increased productivity. The literature on EI from books, published scholarly articles, and blogs are used to frame our argument. We find that corporations need managers to understand EI and personality strategies to enhance their managerial communication effectiveness. Managers will be able to improve their EI skills if they adhere to our 3 key takeaways: 1) master the four EI factors, 2) maintain personal identity by strengthening relationships, and 3) enhance your communication skills with practice.

\section{THE NATURE OF MANAGERIAL COMMUNICATION}

Managerial communication has evolved tremendously since being viewed as a subject that showed promise as a field of research (Bell \& Martin, 2008). In fact, the field has published numerous empirical papers and textbooks (Bell \& Martin, 2019a; Bell \& Martin, 2019b; Hynes, 2019) since 2008. It is impossible to engage successfully in any of the management functions without communication efficacy on at least one of the five levels of communication: intrapersonal, interpersonal, group, organizational, or intercultural (Bell \& Martin, 2019a). Can any manager plan, lead, organize, or control without communication on at least one of the communication levels? It begs the question. For this reason, principles of management textbooks treat communication as a genuine sub-discipline of the leadership 
function of management (Bell \& Muir, 2014); therefore, the managerial communication literature spans across the established areas of the management field.

Managerial communication research covers addiction to the internet that explored differences between men and women on time communicating online (Beaver, et al 2015; Bell, et al 2016). Researchers have explored delegation of authority that examined communication's role in reducing confusion of transferring authority and responsibility (Bell \& Bodie, 2012a). Leaders as catalyst for organizational change used communication to achieve long-term goals (Bell \& Bodie, 2012b). Scientific management was found to be an interpersonal communication skill (Bell \& Martin, 2012). Managerial communication is necessary to understanding the prevalence of the early management theories in modern management approaches (Bell, Kennebrew, \& Blyden 2015). Researchers found that managerial communication was significant on feedback and listening behaviors among international cultures after communication training, and when the gender variable was controlled (Roebuck, et al, 2015; Roebuck et al, 2016). Also, equivalents have been drawn between Drucker's Management by Objectives (MBO) and Tuckman's five stages of team development to synthesize a new theory of Team Management by Objectives, or TMBO (Fulk, Bell, \& Bodie, 2011).

Managerial communication has been shown to be a main topic in papers published by reputable management journals. Celebrity authors were also shown to influence the number of citations of articles published by reputable journals (Bell, 2012a; Bell 2013a). Further studies have been conducted enhancing our understanding of the usefulness of managerial communication research on the main topics of management (Bell \& Roebuck, 2015), and what the most influential management books of the $20^{\text {th }}$ century have to say when compared to bestselling books published as popular press releases (Bell \& Roebuck, 2016). Managerial communication is crucial for achieving strategy from the technical core up to the strategy level of the firm (Bell, 2012b), when communicating trust (Bell, 2012c), when expressing ethics at the technical core of the business among customer service employees (Bell, 2012d), and for more effective conflict resolution, understanding the predictability of uncivil practices of managers, addressing employee's feelings of inequity, and performance appraisals (Bell, 2011; Bell, 2013b; Bell, 2014; ShaneJoyce \& Bell, 2010).

The breadth and depth of managerial communication certainly parallels that of many fields. Like accounting is defined as "the language of business," or business law that might be defined as the organized rules to govern the limits of business behavior, managerial communication is nuanced into the very fabric of managerial behavior, including the emotional fitness of the manager.

\section{Research Purpose}

The managerial communication literature continues to emphasize emotional intelligence (EI) as a critical component in effective managerial communication. Hence, the reason we undertook this study was to further explore the role of managerial communication on EI. Our research addressed how EI affects managerial communication effectiveness. We support this proposition using the definition of EI provided by Salovey and Mayer (1990, p. 186): as "the ability to monitor one's own and others' feelings and emotions, to discriminate among them and use this information to guide one's thinking and actions." The Salovery and Mayer (1990) definition of EI is what we used to operationalize our investigation of the EI literature in relation to managerial communication, assuming its validity.

\section{THE NATURE OF EMOTIONAL INTELLIGENCE}

Harvard Business Review published a recent article which discusses how as managers, we do not expand EI often enough to assist us in our managerial communication practices (Goleman \& Boyatzis, 2017). The deep dive into EI topics helps us understand how managers can best leverage EI to become effective managers and enable organizations to be successful by employing it. There is significant literature about best practices on EI which supports our operational definition.

A main contributing factor for EI is the evolution of the business organization into a more complex integrated system (Prati, Douglas, Ferris, Ammeter \& Buckley, 2003). The shift from manufacturing to 
specialized performance-based jobs caused business organizations to develop into intricate systems with dynamic interchanges among all parties. George (2000) argues EI increases leadership efficiency because it improves the communication process. The status quo for managers has always been to focus on achieving the organization objectives. Effectively executing managerial communication is essential to an organization's overall success. Emotional intelligence enables managers to better assess the communication style, determine the dynamics at play and figure out optimal managerial communication approaches ensuring that employees are able to achieve the desired outcome.

Research suggests that EI is a key ability for effective managerial communication. Daniel Goleman, considered the father of EI, first wrote about its importance in 1995 within various relationship settings. One example of his studies took place in the home and another in the workplace (Goleman et al 2002). He and others (Jennifer George, Peter Salvoey, John Mayer, Moshe Zeidner, Gerald Matthews, and Richard Roberts) have written extensively on myriad themes surrounding the importance of employing EI in diverse environments. Most of our research confirms the prior argument that EI is necessary for effective managerial communication throughout leadership levels. Adele Lynn's (2005) book, "EQ: A Powerful Plan for Putting EI to Work," illuminated the discussion of leaders leveraging EI in the workplace to increase productivity, morale and efficiency in an organization. Travis Bradberry, Jean Greaves, L. Melita Prati, Ceasar Douglas, Gerald Ferris, Anthony P. Ammeter, M. Ronald Buckley, and Rober Kiyosaki have each written articles and published empirical studies delving deeply into how managers can leverage their EI; thereby, contributing to improved efficiency throughout organizational tiers (Bariso, 2018; Sallie-Dosunmu, 2016).

The exact factors of EI are inconsistent in the literature. However, some components of agreement in the literature are: 1) ability to understand ones and other's emotions, 2) ability to regulate one's emotions, and 3) leveraging EI to achieve desired outcomes. It is possible that the next step in EI will be to develop a universally agreed upon methodology eliminating the disparate views of EI factors. A benchmark approach to standardization EI practices would allow scalability to occur as the importance of EI continues to develop. Perception and expectation are fundamentals of managerial communication since successful delivery of a message is as important as the information being delivered (Drucker, 1974). Emotional intelligence in managerial communication often determines whether or not the message is correctly interpreted and appropriate actions are taken to achieve the desired outcome.

\section{Four Factors of EI}

The following factors are taken into consideration when we discuss the emotional factors that may impact an individual's psychological process and behavior: past experiences, personal perspective, feelings, mood and mental triggers (George, 2000). EI in managerial communication might be viewed like the game of Telephone. As the message is transmitted through several of the individual's telephone (emotional filters), depending on how well the original message was created to be delivered, and the understood message may or may not resemble the intended message.

Since our study of EI is qualitative rather than quantitative, there are multiple interpretations of what the key factors of EI might include. Table 1 shows a descriptions of the four factors of EI we derived from the literature, accompanied by known attributes associated with each factor: 1) awareness of self, 2) awareness of others, 3) self-regulation, and 4) relationship management. We believe navigating the attributes of these four factors successfully helps to increase effective managerial communication and should boost team productivity. 
TABLE 1

EMOTIONAL INTELLIGENCE FACTORS AND ATTRIBUTES

\begin{tabular}{|c|c|c|c|}
\hline \multicolumn{4}{|c|}{ EI FACTORS } \\
\hline Awareness of self: & Awareness of others: & Self-regulation: & Relationship management: \\
\hline \multicolumn{4}{|c|}{ AWARENESS ATTRIBUTES } \\
\hline $\begin{array}{l}\text { - Understanding } \\
\text { your role; } \\
\text { - Communication } \\
\text { style; } \\
\text { - Abilities; } \\
\text { - Feelings; } \\
\text { - Mood; and } \\
\text { - Objectives. }\end{array}$ & $\begin{array}{l}\text { - Understanding } \\
\text { other's role; } \\
\text { - Abilities; } \\
\text { - Feelings; } \\
\text { - Mood; and } \\
\text { - Motivation. }\end{array}$ & $\begin{array}{l}\text { - Understanding individual's } \\
\text { role; } \\
\text { - Organizational expectation; } \\
\text { and } \\
\text { - Controlling actions to avoid } \\
\text { contradiction in } \\
\text { communication. }\end{array}$ & $\begin{array}{l}\text { Leveraging emotional } \\
\text { intelligence to achieve } \\
\text { desired outcome. }\end{array}$ \\
\hline
\end{tabular}

The first factor of EI is awareness of self which starts with an individual understanding their role, communication style, abilities, feelings, mood and objectives. This assessment allows an individual to leverage their strengths, focus on the objective, and identify potential weaknesses in their communication that needs to be refined.

The second factor awareness of others centers on the recipient of the communication with establishing rapport, tailoring our message to the audience achieving the desired outcome and anticipating potential challenges. Drucker (1974) discusses at length how people tend to misinterpret, resent or ignore communication that does not meet their expectation. Awareness of others requires empathy and attention to non-verbal cues such as visual, body language and environmental factors (George, 2000 cited in Prati, Douglas, Ferris, Ammeter, \& Buckley, 2003).

The third factor self-regulation requires an understanding the individual's role, expectation in the organization and controlling our actions, which may be viewed as a form of contradictory communication (Prati, Douglas, Ferris, Ammeter, \& Buckley, 2003). This factor may be the hardest part of EI to achieve especially in stressful situations. In a professional setting, it is always best to exercise self-restraint and access the situation before reacting to avoid sabotaging the effectiveness of our communication.

Finally, the fourth factor relationship management leverages all the other factors establishing the relationship between ourselves and the targeted audience while executing the managerial communication for achieving the desired outcome. That outcome can be to influence, mentor, motivate, inspire or resolve conflict (Goleman \& Boyatzis, 2017). In Bell's (2012c) article, "Three facets for communicating managerial trustworthy behavior," the author discusses the importance of establishing a trusting managerial relationship by providing "accurate information;" then, "explaining your managerial decisions" and ultimately establishing "open communication." This article emphasizes the significance of all the factors of EI to achieve the desired outcome of establishing trust in the organization.

\section{UTILIZING EI IN MANAGERIAL COMMUNICATION}

Having certain educational credentials and work experience are not enough to become an effective leader. Paying attention to your emotions and practicing self-control helps to ensure that you are rational. The communication between your emotional and rational "brains" is the physical source of EI (Bradberry $\&$ Greaves, 2009). This plays a major part in how you communicate as a manager and how your team views you as a leader. The perception of the leader dictates the work environment and the overall cohesiveness of the team.

Emotional intelligence is your ability to recognize and understand emotions in yourself and others, and your ability to use this awareness to manage your behavior and relationships (Bradberry \& Greaves, 
2009). Management lacking high EI run the risk of having avoidable conflict amongst the team. Reacting too quickly based on feelings can be detrimental to the team and interfere with achieving company goals. Your objective is to preserve relationships, not to create adversaries (Brown, Haygood \& McLean, 2010). Feeding off the emotions of others to engage in a conversation, and to connect with them builds the foundation of trust between management and employees. We imitate each other's emotions as a way of expressing support and caring and, even more basically, as a way of communicating with each other (Gladwell, 2002). Connecting, showing empathy and understanding towards your team's perspective does not mean that your professional expectations or goals change. An effective manager can still hold their team accountable for outcomes and address inefficiencies; however, this will look, and sound differently based on if the manager has high EI.

\section{Personalities in Work Environments}

Our success as a manager depends on our ability to communicate effectively (Bell \& Martin, 2014). The four basic business personalities are: relater, socializer, thinker, and director. Understanding how to effectively communicate with the four basic personalities can increase the successful delivery of our communication. To ensure that our message is understood by the receiver, it is important to know exactly who the receiver is. Utilizing your EI skills allows us to adapt our methods and use the correct communication style that fits the receiver's personality and behavior.

Effective dialogue requires you to tap into your knowledge of psychology which is defined as "the mental or behavioral characteristics of an individual or group." Taking the necessary time to discover who the recipients are allows you to deliver a message that insures the information received is clear and concise. Connecting with individuals is how you will learn more, inspire more and encourage those persons make more useful things happen (Parker, 2012). That connection occurs by paying attention to the desired recipients. Observing others and listening to the things they say can give you an idea of who they are and how they want to be treated. People unknowingly send you signals everyday telling you about how they want to be treated. Verbal, vocal and visual cues are keys to understanding anyone's behavioral style (Alessandra \& O'Connor, 1996).

We enter the workforce knowing how to read write, and report on bodies of knowledge, but too often we lack the skills to manage emotions in the heat of the challenging problems that we encounter (Bradberry \& Greaves, 2009). Robert T. Kiyosaki, the best-selling author of the Rich Dad Poor Dad series, states that traditional schools focus on one thing only: your mental ability. If you solve equations and do well on tests, then you're considered smart enough to run a company (Kiyosaki, 2010). Managers must have more than the technical skills to become a successful leader within an organization. Robert $\mathrm{T}$. Kiyosaki references that his success comes from training in the Marines. Military schools prepare you to be a great leader by focusing not only on your mind, but also on your emotional, physical and spiritual abilities (Kiyosaki, 2010).

Over the years, corporations have started to see the importance of employing EI in the work place. This was bolstered by research assessments which show the hidden value and correlations of emotions and labor in that environment.

These studies have shown how businesses are hiring individuals based on more than just their technical skills and educational background (Ashforth \& Humphrey, 1995). Hiring managers are looking for employees with the emotional and social skills to help grow their business units.

Emotion, as the root to EI, is figured has become an important part of job performance. In the past, cognitive intelligence was perceived as the most important predictor to job performance. Todays' millennials think differently than their predecessors making EI a more relevant consideration (Goleman, 2006). Organizational decisions are being driven on the emotional patterns of their employees, but these same patterns have a positive and negative effect on the end goal. While the positive part of said emotions can bring group unity and focus on subject matter, the negative side also delivers a divide within the group attempting to reach their end goal. Depending on the emotion being expressed and how it affects the others participating, it can have an alternate meaning to the intended emotion being expressed. 


\section{Toxic Work Environments}

Emotional intelligence can be employed within a toxic work environment to alleviate unintended consequences. Work conflict often happens from different views between individuals or groups. The resolution forces individuals to be personally realistic and step out of the process while addressing the issues at hand (Hughes \& Terrell, 2012). A work environment unpleasant or toxic based on several factors. Most studies show that such instances revolve around organizational/occupational stress. Stresses can be caused by time restraints, work deadlines, excessive traveling or work place changes (Kite \& Kay, 2012).

Looking deeper into occupational stress and how EI is factored in, one gets to see the organization and personal perceptions from either top level, middle level or frontline management. This also requires one to take into consideration peer perceptions and how those can contribute to stress. This invites one to view the understanding of management and peers based on the ability to analyze, process and make decisions during stressful situations. The ability to cope and continue to compartmentalize difficult situations to achieve the main goal is a great thing. However, this dictates one to must monitor and maintain the emotional expression. Peer relationships are vital for a group to prosper, but a toxic work environment could derail the group from reaching their objectives.

Occupational stress can deteriorate ones' health from a daily, stressful grind (Zeidner, Matthews, \& Roberts, 2012). This stress can also contribute to individuals having problems at home and possible substance issues or abuse. In a toxic work place these same stresses can contribute to work place violence and bullying. To rectify these issues, we have seen organizations promote EI methodology (Katzenbach \& Smith, 1993). Adding this methodology to an organization allows the unit to work in greater harmony and reach their set of goals. Embracing of EI and with managers providing certain forms of stress relievers such as counseling, interventions and even one-on-one conversation off the record help change a toxic work environment. Our documentation shows the benefits of how the implementation of EI increases the team building structure if properly used, allowing for better communication channels and expression of individuals feelings and emotions toward subject matter.

Emotional intelligence is beneficial to today's business sector. Grasping the knowledge and fundamentals of this process can help propel an organization in the right way to accomplishing their goals (Stein \& Book, 2006). We have seen how proper communication at all levels allow the team to grow and materialize to a cohesive unit.

\section{THE 3 KEY TAKEAWAYS}

Emotional intelligence is being able to understand one's own emotions as well as recognizing and understanding the same in others. EI composed of four factors: awareness of self, awareness of others, self-regulation, and relationship management. Managers utilizing the four factors of EI will be able to identify their strengths to leverage in communication and weaknesses that require improvements. Managers are looking for personnel that are willing to be emotionally invested as well as physically invested in achieving the organizational goals (Ashkanasy, Hartel \& Daus, 2002).

The physical source of EI can be explained as communication between your emotional and rational brains. The heart generates the emotional component. Hormones are produced within the body in certain situations creating electromagnetic signals to the brain. The brain then triggers reactions, signals and responses without an individual having the opportunity to consider them rationally (Hughes \& Terrell, 2012). We know that we imitate each other's emotions as a way of expressing support and caring and, even more basically as a way of communicating with each other (Gladwell, 2002).

Leveraging EI in today's work environments can help to reduce occupational stress, increase effective communication between generation gaps, and reduce conflict in toxic work environments. Observing and enhancing our EI skills should be done with every interaction. Continuous effort to improve EI will lead to enhanced communication skills, better team environments, and increased productivity. 
The 3 key takeaways from our findings for excellent EI is to: 1) master the four EI factors, 2) maintain your personal identity by strengthening relationships, and 3) enhance your communication skills with practice.

\section{First, Master the Four EI Factors}

Understand the four EI factors and the real world applications (Bradberry \& Greaves, 2009). Pick one of these EI factors to work on and implement strategies to help you enhance the skill. If self-awareness is the area that you want to focus on, take the time to visit your core values. Write a list of things that make you upset as well as happy and explain why they make you feel that way. Figure out what your triggers are and why these things get under your skin. Really get to know yourself and while doing so, check yourself. You may find while making your list and writing your rationale behind the list that some modifications need to be made.

Since self-management is using your emotions to dictate what you say or do, you may try taking deep breaths or counting to 10 before responding. When receiving bad news or confronted with a tough situation, do you respond or react? Reactions occur quickly and are stemmed directly from emotions. Over reaction is not the best way to handle a situation. When you respond to a situation, you slow down and take the time to process the information. Having EI will help you to take control of your emotions and manage yourself. A recommendation for self-management is to stay open-minded and look at each situation you encounter as an opportunity to learn and grow.

Social awareness is about recognizing emotions of others and yourself. Pay attention to the visual cues that you give off such as body language and facial expressions. What energy are you feeding to others, and what energy are you receiving based on your communication style? You can speak with your body even louder as you can speak vocally. Watch yourself by looking in the mirror. Grab a partner and ask them to pay attention to you as well. Do you roll your eyes? Fold your arms? Appear closed-minded? Make sure that your actions and body language are sending the correct message so that the receiver is not distracted or lost with what you are trying to convey.

Relationship management is centered on maintaining and building relationships. Focus on creating trust amongst your team. Create this foundation by building rapport, being open, showing empathy and understanding other's views. Take interest in your team members by asking them about their family and personal interests. Open up and share back information about yourself. Make it fun and incorporate team building activities. Most importantly throughout this EI skill, be genuine. Relationships can be damaged, and trust will be broken if you are untrue.

\section{Second, Maintain Your Personal Identity by Strengthening Relationships}

Emotional intelligence is not about changing who you are to become someone else, but it is about understanding and adapting so that you can effectively communicate and lead your team. Adaptability doesn't mean mimicking another person's style. It doesn't mean abandoning your identity or your good business sense. It just means adjusting your openness and directness, your pace and priority, to make this relationship work (Alessandra \& O'Connor, 1996).

Observe your team to discover if they are a director, relater, socializer, or a thinker. Pay attention to their body language, their personality, and the words that they say. Once you understand the audience, apply the Platinum Rule which is to treat others how they want to be treated (Alessandra, \& O'Connor, 1996). If your team member is a director, stay professional, be organized and make your point quickly. Directors are impatient and make swift decisions. If your team member is a relater, speak slowly, stay sincere and show personal interest in them. Relaters are active listeners and enjoy one on one interaction. If your team member is a socializer, use visuals and bring energy. A socializer is outgoing and will get bored easily. You have to grab their attention but remember to stay focused. To adapt to a thinker come prepared with as many details as possible along with supporting documents. Thinkers are very thorough and like the facts. 


\section{Third, Enhance Your Communication Skills with Practice}

Build better team environments and increase overall productivity using excellent managerial communication skills. Observing and enhancing your EI skills should be done with every interaction that you make. Practicing kaizen in EI creates effectiveness of Managerial Communication horizontally and vertically throughout a corporation. Kaizen is the Japanese word for "improvement." In business, kaizen refers to activities that continuously improve all functions and involve all employees from the CEO to the assembly line workers (Kaizen, n.d.). The more you practice and pay attention to your audience, the easier it will become for you to quickly adjust. Actively measure your progress and come up with new strategies.

Find a mentor and seek feedback. How you think you may come across may not be the perception of others. Feedback from a mentor is a good communication skill used to measure yourself on tough to recognize frailties that you might be exhibiting. Stay open to the recommendations that you receive and view the advice as an opportunity to actually see yourself to get better.

\section{REFERENCES}

Alessandra, T., \& O'Connor, M. J. (1996). The platinum rule: discover the four basic business personalities - and how they can lead you to success. USA: Grand Central Publishing.

Ashforth, B., \& Humphrey, R. (1995). Emotion in the workplace: A reappraisal. Human Relations 48, 97125.

Ashkanasy, N. M., Härtel, C. E. J., \& Daus, C. S. (2002). Diversity and emotion: The new frontiers in organizational behavior research. Journal of Management, 28(3), 307-338.

Bariso, J. (2018). EQ Applied: The real-world guide to emotional intelligence. Germany: Borough Hall.

Beavers, L., Bell, R.L., Guyot, W., Meier, R., \& Choudhury, D. (2015). Online time and gender perceptions of internet addiction. Journal of Higher Education Theory and Practice 15 (3), 84-98.

Bell, R. L. (2011). Addressing employee's feelings of inequity: capitalizing on equity theory in modern management. Supervision, 72(5), 3-6.

Bell, R. L. (2012a). An empirical investigation of communication content in reputable management journals. Business Studies Journal, 4(1), 21-44.

Bell, R. L. (2012b). Communicating strategy at the technical core. Supervision, 73 (10), 3-7.

Bell, R. L. (2012c). Three facets for communicating managerial trustworthy behavior. Supervision, 73(11), 16-20.

Bell, R. L. (2012d). Using practical ethics to improve customer service on the frontline. Supervision, 73(8), 3-6.

Bell, R. L. (2013a). Management journals and the celebrity researcher effect on tiers. Journal of Leadership, Accountability and Ethics, 10(5), 44-62.

Bell, R. L. (2013b). Removing the source of conflict from conflict situations. Supervision, 74(11), 3-6.

Bell, R. L. (2014). Performance appraisals and the cognitive domain. Supervision, 75(7), 3-7.

Bell, R. L., \& Bodie, N. D. (2012a). Delegation, authority and responsibility: Removing the rhetorical obstructions in the way of an old paradigm. Journal of Leadership, Accountability and Ethics, 9(2), 94-108.

Bell, R. L., \& Bodie, N. D. (2012b). Leaders as catalysts for organizational change: How popular press business books address the topic. Journal of Organizational Culture, Communications, and Conflict, 16(1), 49-70.

Bell, R. L., Kennebrew, D., \& Blyden, L. A. (2015). An increasing utility for the early management theories: An exploratory study. International Journal of Management and Human resources, 3(1), $1-23$.

Bell, R. L., \& Martin, J. S. (2008). The promise of managerial communication as a field of research. International Journal of Business and Public Administration, 5(2), 125-142.

Bell, R. L., \& Martin, J. S. (2012). The relevance of scientific management and equity theory in everyday managerial communication situations. Journal of Management Policy and Practice, 13(3), 106-115. 
Bell, R. L., \& Martin, J. S. (2014). Managerial communication. United States of America: Business Expert Press, LLC.

Bell, R. L., \& Martin, J. S. (2019a). Managerial communication for organizational development. USA: Business Expert Press, LLC.

Bell, R. L., \& Martin, J. S. (2019b). Managerial communication for professional development. USA: Business Expert Press, LLC.

Bell, R. L., \& Muir, C. (2014). A review of business communication under the leadership function. Business Studies Journal, 6, 99-121.

Bell, R. L., \& Roebuck, D. B. (2016). An examination of differences between the most influential management books of the $20^{\text {th }}$ century and amazon best sellers. International Journal of Business Research and Information Technology, 3(1), 35-78.

Bell, R. L., \& Roebuck, D.B. (2015). An increasing usefulness for managerial communication research on the main topics of management. Journal of Management Policy and Practice, 16(2), 71-108.

Bell, R. L., Choudhury, D., Guyot, W. M., \& Meier, R. J. (2016). Impulse control and internet addiction disorder among business professionals. Journal of Organizational Culture, Communications and Conflict, 20, 1-19.

Bradberry, T., \& Greaves, J. (2009). Emotional intelligence 2.0. United States of America: Talent Smart.

Brown, E. M., Haygood, M., \& McLean, R. J. (2010). The little black book of success: laws of leadership for black women. USA: One World Books.

Drucker, P. F. (1974). Management: Tasks, responsibilities, practices. New York: Harper \& Row, Publishers.

Fulk, K. H., Bell, R. L., \& Bodie, N. D. (2011). Team management by objectives: Enhancing developing teams' performance. Journal of Management Policy and Practice, 12(3), 17-26.

George, J. M. (2000). Emotions and leadership: The role of emotional intelligence. Human Relations, 53(8), 1027-1055.

Gladwell, M. (2002). The tipping point: how little things can make a big difference. United States of America: Little, Brown and Company.

Goleman, D. (2006). Working with emotional intelligence. New York, NY: Bantam Dell.

Goleman, D., \& Boyatzis, R. E., (2017, February 06). Emotional intelligence has 12 factors. Which do you need to work on? Harvard Business Review. Retrieved from https://hbr.org/2017/02/emotional-intelligence-has-12-factors-which-do-you-need-to-work-on.

Goleman, D., Boyatzis, R., McKee, A., \& Patterson, S. (2002). Primal leadership: Realizing the power of emotional intelligence. Boston, MA: The Harvard Business School Press.

Hughes, M., \& Terrell, J. (2012). Emotional Intelligence in Action: Training and Coaching Activities for Leaders, Managers, and Teams. San Francisco: Pfeiffer.

Hynes, G. E., \& Veltsos, J.R. (2019). Managerial communication: Strategies and applications, $7^{\text {th }}$ Edition. SAGE Publications, Inc.

Kaizen. (n.d.). In Wikipedia, Free Encyclopedia. Retrieved from https://en.wikipedia.org/wiki/Kaizen Katzenbach, J., \& Smith, D. (1993). The Wisdom of Teams. Boston, MA: Harvard Business School Press. Kite, N., \& Kay, F. (2012). Understanding emotional intelligence: Strategies for boosting your EQ and Using It in the Workplace. India: Kogan Page Limited.

Kiyosaki, R. T. (2010). The business of the 21st century. United States of America: Dream Builders.

Lynn, A. B., (2005). EQ Difference: A Powerful Plan for Putting Emotional Intelligence to Work. United States of America: AMACOM.

Parker, S. (2012). Lead [simply]. Richmond, VA: Give More Media Inc.

Prati, L. M., Douglas, C., Ferris, G. R., Ammeter, A. P., \& Buckley, M. R. (2003). Emotional intelligence, leadership effectiveness, and team outcomes, The International Journal of Organizational Analysis, 11(1), 21-40.

Roebuck, D. B., Bell, R. L., Raina, R., \& (Catherine) Lee, C. E. (2015). The effects of home country, gender, and position on listening behaviors. Journal of Organizational Culture, Communications and Conflict, 19(2), 93-120. 
Roebuck, D. B., Bell, R. L., Raina, R., \& Lee, C. E. (. (2016). Comparing perceived listening behavior differences between managers and nonmanagers living in the United States, India, And Malaysia. International Journal of Business Communication, 53(4), 485-518.

Sallie-Dosunmu, M. (2016). Using emotional intelligence in the workplace, 33(1612).

Salovey, P., \& Mayer, J. D. (1990). Emotional intelligence: Imagination, Cognition and Personality, 9(3), $185-211$

Shane-Joyce, M. P., \& Bell, R. L. (2010). Communication practices of managers and the predictability of uncivil communication in response. International Journal of Business and Public Administration, 7(2), 37-51.

Stein, S. J., \& Book, H. E., (2006). The EQ Edge: Emotional Intelligence and Your Success. Canada: Printcrafters.

Zeidner, M., Matthews, G., \& Robert, R. (2012). What we know about emotional intelligence: How it affects learning, work, relationships, and our mental health. Cambridge, MA: MIT Press. 